\title{
Evaluation of genotoxicity of monocrotophos and quinalphos in rats and protective effects of melatonin
}

\author{
Vibhuti Mishra, Sapneh Sharma, Shilpa Khatri and Nalini Srivastava* \\ School of Studies in Biochemistry, Jiwaji University, Gwalior 474 011, India
}

\begin{abstract}
Monocrotophos [dimethyl-[E]-1-methyl-2-(methyl carbamoyl) vinyl phosphate, MCP] and quinalphos [O,O-diethyl-o-(2-quinoxymethyl)-phosphorothionate, QNP] are highly toxic, broad spectrum and cholinesterase inhibiting pesticides which are extensively used in agriculture and household. Acute and chronic exposure of these pesticides has adverse effects on living organisms. Present study was carried out to evaluate the genotoxic potential of these pesticides using comet assay and micronucleus assay in rats and also to analyze the protective effects of melatonin. Both acute and chronic exposure caused DNA damage in rat tissues and lymphocytes as evident from the statistically significant increase in DNA damage index on pesticide exposure. However the co-treatment of melatonin decreased the damage index to significant levels. At the same time, statistically significant number of micronuclei was observed in polychromatic erythrocytes (PCE) in the bone marrow of rats treated with pesticides when compared to control group but the co-treatment of melatonin decreased the number of micronucleated PCE in the pesticide treated rats. Hence, the co treatment of melatonin has the ability to reduce the genotoxic potential of MCP and QNP under the experimental conditions applied in the present study.
\end{abstract}

\section{Introduction}

Pesticides are highly toxic compounds extensively used for the eradication of a variety of pests in agriculture, forestry and household. The indiscriminate use of pesticides in agriculture and public health purposes has caused serious environmental and health problems to the non-target organisms including human, cattle, aquatic and terrestrial lives, predators, pollinators etc. as only $1 \%$ of the applied pesticides reach to the target. It has been estimated that more than 500,000 cases of severe poisoning, and 346,000 deaths are caused worldwide annually and two thirds of them occur in developing countries [1]. Among the various types of pesticides, organophosphates (OPs) are the most extensively used group of chemicals. The OP pesticides exert their toxic effects by blocking acetylcholinesterase (AChE) leading to accumulation of acetylcholine at synapses and neuromuscular junctions. The accumulation of acetylcholine leads to hyperactivation of the receptors resulting in immediate neurological dysfunctions and repeated, uncontrolled firing of neurons resulting in death usually by asphyxiation as respiratory control is lost. The rapidity of accumulation depends on the doses of the pesticide. The vital organs adversely affected by OP poisoning are brain, liver, kidney, muscles, immune system and hematological system. Besides being potent neurotoxic agents, the OP pesticides are known to produce oxidative stress by increasing the production of reactive oxygen species (ROS) and inhibiting both enzymatic and non-enzymatic antioxidant defenses [2]. Extensive data suggest that enhanced oxygen free radical formation is a major contributor to the toxicity of pesticides. The main sources of the production of ROS are metabolism of OPs by cytochrome P450s and the high energy consumption coupled with inhibition of oxidative phopsphorylation [3].

The generation of reactive oxygen species (ROS) is both beneficial to cells, performing a function in inter- and intracellular signalling, and detrimental, damaging cellular biomolecules, accumulation of which has been associated with numerous diseases. Oxidative DNA damage is an inevitable consequence of cellular metabolism, with a propensity for increased levels following toxic insults due to exposure with various environmental chemicals, radiations, metals and pesticides. DNA damage and oxidative stress have been proposed as mechanism that could mechanistically link pesticide exposure to a number of health outcomes observed in epidemiological studies [4,5]. There are many reports describing elevated levels of oxidatively modified DNA lesions, in various biological matrices, in a large number of diseases which include cancer, Parkinson's disease, Alzheimer's disease, atherosclerosis, heart failure, myocardial infarction, Schizophrenia, bipolar disorder, fragile $\mathrm{X}$ syndrome, sickle cell disease and chronic fatigue syndrome [6].

OP pesticides have been widely studied for their ability to induce damage to DNA in in vivo as well as in vitro systems and have demonstrated genotoxic, alkylating and clastogenic properties. OP pesticides induced DNA damage is reported by many workers and these compounds have been shown to be genotoxic [7-10]. Profenofos is known to cause DNA damage in gill tissues of freshwater fish, Channa punctatus (Bloch), at different concentrations and different time points [11]. Organophosphate pesticides cause cumulative toxicity with organochlorine pesticides. Their toxic effects include estrogenic disruption and OP induced delayed neuropathy [12]. Fenthion and terbufos cause death in Hep G2 cells on acute exposure in concentration dependent manner. Tumor related genes (jun, myc,

Correspondence to: Professor Nalini Srivastava, School of Studies in Biochemistry, Jiwaji University, Gwalior 474 011, India, Tel: 91751 2442796; Fax: 91751 1341450; E-mail: nalinis21@yahoo.com

Key words: monocrotophos, quinalphos, comet assay, genotoxicity, micronucleus test

Received: January 03, 2015; Accepted: February 18, 2015; Published: February 24,2015 
and fos) and apoptosis- related genes (socs 3, tnfaip 3, ppp1r15a and nr4a1) are upregulated by these compounds [13].

Monocrotophos [dimethyl-(E)-1-methyl-2-(methyl carbamoy) vinyl phosphate, MCP], a highly toxic, systemic aliphatic OP insecticide used to control a variety of sucking, chewing and boring insects, spiders, mites on cotton, sugarcane, peanuts, ornamentals and tobacco [14] while quinalphos [O,O-diethyl-O-(2- quinoxalinyl)phosphorothioate, QNP] is a widely used insecticide and acaricide which is highly toxic to non-target organisms such as humans and vertebrate animals [15]. The secondary metabolite of quinalphos, 2-hydroxyquinoxaline, is likely to be responsible for its toxic effects such as estrogenic/ antiandrogenic actions, oxidative stress, decrease of the radical scavenger melatonin, impairment of immune response, chromosomal aberration and micronuclei formation etc. [16]. Quinalphos has also been attributed to induce chromosome breaks/ fragments in mice and human lymphocytes [17]. The genotoxic and mutagenic potential of MCP has been proved by several tests and shown to induce chromosome aberrations also [18]. MCP has also been reported to alter expression of certain cytochrome P450s in PC12 cells [19] and exert toxic effects on the male reproductive functions [20]. Various OP pesticides such as malathion and parathion have also been studied extensively and are known to induce DNA damage in the form of chromosomal aberrations, mitotic index and sister chromatid exchanges (SCE) in both human and animal studies [21,22].

Melatonin (N-acetyl-5-methoxytryptamine) is a ubiquitous molecule studied extensively for its antioxidant properties. The main source of melatonin in mammals is pineal glands. Being a powerful free radical scavenger, it is involved in both direct and indirect antioxidant functions and has the ability to remove $\mathrm{H}_{2} \mathrm{O}_{2}, \mathrm{OH}$, peroxynitrite anion, singlet oxygen, $\mathrm{O}_{2}{ }^{-}$and peroxyl radicals [23]. Melatonin has the ability to interact with free radicals through consecutive reactions giving rise to many stable compounds that can be excreted by the body [24]. It has been reported that the ability to recruit exogenous melatonin varies from tissue to tissue and tissues which accumulate more melatonin presented higher levels of antioxidant defense [25]. Melatonin is known to prevent the damage caused by OP pesticides such as diazinon and malathion [26,27]. Melatonin is also known to reduce the levels of trace and major elements which increase in response to fenthion intoxication [28].

Monocrotophos (MCP) and quinalphos (QNP) are extensively used OP pesticides throughout the world including India. These pesticides are known to induce oxidative stress and cause alterations in the redox status of the tissues in rats. While several reports are available in literature on the genotoxic effect of MCP using various in vivo and in vitro systems, QNP has not been tested for its genotoxic potential. Moreover, the combined toxicity of these pesticides has also been not studied. The single cell gel electrophoresis (SCGE) or comet assay, is a rapid and sensitive technique to demonstrate the damaging effects of different chemical compounds or physical treatments on DNA at individual cell levels. The assay is a quick, simple, reliable, easy to perform, inexpensive method of analyzing genotoxicity [29,30]. This assay is widely used in testing genotoxicity, human biomonitoring and fundamental research on DNA damage and repair [31]. The advantage of comet assay include a high sensitivity for detecting low levels of DNA damage, the requirement for small number of cells per sample, and its flexibility. On the other hand the micronucleus assay is a biomonitoring test used to analyze the genotoxicity associated with pesticide exposure [32]. The in vivo micronucleus assay is widely used to analyze the clastogenic and aneugenic potential of chemicals [33], and is now recognized as one of the most reliable assays for screening genotoxic carcinogens. The number of reports from micronucleus test has increased in the scientific literature and the value of this test for examining the mutagenicity and carcinogenicity of chemicals, has been emphasized, particularly when it is used in combination with other cytogenetic assays. It is simple, inexpensive, accurate and can be applicable to different cell types [34].

As a range of pesticides is extensively used in pest management, the chances of exposure of multiple pesticides simultaneously are high, especially among agricultural and public health workers. Furthermore, there may be separate but closely timed exposures to such insecticides. Although health hazards of individual OP pesticide have been relatively well characterized, the interactive toxicity on combined exposure of these pesticides is not clearly known. Since MCP and QNP are widely used pesticides, the chances of their overlapping applications are high. Therefore, it was considered worthwhile to evaluate the genotoxic effects of MCP and QNP, singly and in mixture, in various tissues of rats given acute or chronic exposure using comet assay and micronucleus assay. In addition, it was also evaluated if such damage could be repaired by melatonin co-treatment.

\section{Material and methods}

\section{Chemicals and reagents}

TRIS base, sodium chloride, sodium hydroxide, sodium acetate, dimethyl sulfoxide, triton X-100, Giemsa stain, fetal bovine serum, melatonin, ethylenediaminetetraacetic acid tetrasodium salt, agarose (normal melting and low melting), cyclophosphamide and ethidium bromide were purchased from Sigma Chemical Co., St. Louis, Mo. Sarcosine, DPX mountant for microscopy was obtained from Merck, Germany. The pesticides, monocrotophos and quinalphos, were a kind gift from Gujarat Insecticides Limited, Ankleshwar, Gujarat, India.

\section{Experimental animals}

Adult male albino rats of Wistar strain (Rattus norvegicus), 8-weeks old, weighing about $120 \pm 10 \mathrm{~g}$ were used in the present study. Rats were obtained from the animal facilities of Defence Research and Development Establishment, Gwalior, India, and were maintained in a light (light-dark cycle of $12 \mathrm{~h}$ each) and temperature $\left(25 \pm 2^{\circ} \mathrm{C}\right)$ controlled animal room of our department on standard pellet diet (obtained from in the Amrut Rat \& Mice Feed, New Delhi, India) and tap water ad libitum. Rats were acclimatized for one week prior to the start of the experiment. The care and maintenance of animals were as per the approved guidelines of the 'Committee for the Purpose of Control and Supervision of Experiments on Animals' (CPCSEA, India).

\section{Study design}

For acute or chronic studies, rats were divided into two groups, one group received only pesticides either singly or in mixture while the other group received co-treatment of melatonin and pesticide for the same period of time. The acute exposure was given for two consecutive days whereas chronic exposure was given for sixty days. Each sub group contained six rats. Blood was withdrawn and lymphocytes were separated $24 \mathrm{~h}$ after the last treatment, rats were humanly sacrificed and liver and brain tissues were excised off, and processed for comet assay. The bone marrow from both the femurs was aspirated, processed and smears were prepared for micronucleus assay. 


\section{Pesticide treatment}

Acute exposure: The animals were randomly divided into two groups, which were further divided into four subgroups of six animals each. The rats of first group consisted of twenty four animals which were further divided into four subgroups of six animals each and were given pesticides for two consecutive days. The second group consisted of thirty animals divided into five subgroups of six animals each, received co treatment of pesticide and melatonin for two consecutive days. The rats of first sub group received $\mathrm{MCP}\left(0.25 \mathrm{LD}_{50}\right.$ i.e. $4.5 \mathrm{mg} /$ $\mathrm{Kg}$ body weight dissolved in $0.4 \mathrm{ml}$ corn oil per day, orally for two consecutive days [35]), the second sub group received QNP $\left(0.25 \mathrm{LD}_{50}\right.$ i.e. $5 \mathrm{mg} / \mathrm{Kg}$ body weight per day [36]), the third sub group received a mixture of both the pesticides $\left(0.125 \mathrm{LD}_{50}\right.$ each, total $0.25 \mathrm{LD}_{50}$ equivalent $/ \mathrm{Kg}$ body weight for two consecutive days), while rats of the fourth sub group received $0.4 \mathrm{ml}$ corn oil orally for two days and served as the control. The rats of the second group were divided into four sub groups, the first, second, third and fourth sub groups received a co treatment of melatonin $(5 \mathrm{mg} / \mathrm{Kg}$ body weight intraperitoneally per day for two consecutive days [37]) and MCP, QNP, mixture or corn oil as in the first group. In case of micronucleus assay a sub group of six animals received cyclophosphamide $(40 \mathrm{mg} / \mathrm{Kg})$ body weight orally for two consecutive days and served as the positive control.

Chronic exposure: For chronic studies the animals were divided into two groups of twenty four animals each which were further sub divided into four subgroups of six animals each. The rats of first, second and third sub group received MCP, QNP and mixture of MCP + QNP dissolved in $0.4 \mathrm{ml}$ corn oil, orally for 60 days (the doses were $\mathrm{LD}_{50} /$ 60 per day, receiving total $\mathrm{LD}_{50}$ equivalent in 60 days), the fourth sub group received equivalent volume of corn oil for the same period of time and served as the control. Likewise the rats of second group were divided into four subgroup and were given $5 \mathrm{mg} / \mathrm{Kg}$ body weight melatonin intraperitoneally daily for sixty days along with MCP, QNP, $\mathrm{MCP}+\mathrm{QNP}$ and corn oil orally per day as in the first group. In another group, same numbers of rats were taken and were given either $\mathrm{LD}_{50} / 30$ equivalent of MCP, QNP and their mixture per day receiving total 2 $\mathrm{LD}_{50}$ equivalent in 60 days, or co-treatment of pesticide and melatonin as the rats of the first group.

In case of micronucleus assay, a sub group of four animals received cyclophosphamide (10mg/Kg body weight) orally for sixty days which served as the positive control.

\section{Collection of blood, isolation of lymphocytes and tissues collection}

The blood was collected $24 \mathrm{~h}$ after the last treatment via ocular bleeding in tubes containing EDTA from the animals for lymphocyte separation. Blood samples were layered on the top of a Ficoll solution $(1.077 \mathrm{~g} / \mathrm{ml})$ and the supernatant containing the leukocytes was removed after sedimentation of erythrocytes at $1000 \mathrm{~g}$ for $10 \mathrm{~min}$ at room temperature. Lymphocytes sedimented at the interface of the Ficoll layers were collected and washed twice with phosphate buffer saline (PBS), pH 7.4. The cell viability was checked by trypan blue dye exclusion test [38]. The lymphocytes samples with viability $>95 \%$ were used for comet assay.

After the blood collection, the rats were humanly killed by cervical dislocation; liver and brain tissues were excised off, washed with $0.9 \% \mathrm{NaCl}$ and used for different estimations. Animals were handled, ethically treated and humanly killed as per the rules and instructions of Ethical Committee of Animal Care of Jiwaji University, Gwalior, India, in accordance with the Indian National law on animal care and use.

\section{Comet assay}

Alkaline single cell gel electrophoresis was performed by the method of Sasaki et al. [39] for estimation of DNA single strand breaks whereas neutral version of comet assay was performed by the method of Wojewodzka et al. [40] for measuring double strand breaks. A homogenate $(25 \% \mathrm{w} / \mathrm{v})$ of fresh tissues was prepared in chilled homogenizing buffer $(0.075 \mathrm{M} \mathrm{NaCl}$ containing $0.024 \mathrm{M}$ EDTA, $\mathrm{pH}$ 7.2) in a Potter Elvehjem homogenizer with a single stroke. The nuclei were obtained by centrifugation at $700 \mathrm{~g}$ for $10 \mathrm{~min}$ at $4{ }^{\circ} \mathrm{C}$ and the pellet was gently resuspended in $3.0 \mathrm{ml}$ of chilled homogenizing buffer. Seventy five $\mu \mathrm{l}$ of normal melting agarose (1\% prepared in $0.1 \mathrm{M}$ sodium phosphate buffer, $\mathrm{pH} 7.2$, containing $0.9 \% \mathrm{NaCl}$ ) was quickly layered on end-frosted slide, covered gently with another slide, and allowed to solidify. The upper slide was carefully removed and the precoated slide was coated with $100 \mu$ l of a mixture containing equal volumes of sample (nuclei preparation) and low melting agarose ( $2 \%$ in phosphate buffer saline). Slides were then immersed in the lysis buffer (containing 2.5M NaCl, 100mM EDTA, $10 \mathrm{mM}$ Tris base, $1 \%$ sarcosine, $\mathrm{pH} 10.0$ adjusted with $10 \mathrm{~N} \mathrm{NaOH}$ and $5 \%$ DMSO and $1 \%$ Triton X-100 were added just before use) for $1 \mathrm{~h}$ at $4^{\circ} \mathrm{C}$ in dark. After lysis, the slides were rinsed with chilled distilled water, transferred on a horizontal electrophoresis platform and immersed in electrophoresis buffer [300mM sodium hydroxide and $1 \mathrm{mM}$ EDTA, $\mathrm{pH}>13.0$ for single strand breaks; $300 \mathrm{mM}$ sodium acetate and $100 \mathrm{mM}$ Tris ( $\mathrm{pH} 9.0)$ for DNA double strand breaks]. After electrophoresis, the slides were washed thrice with neutralizing buffer (0.4M Tis- $\mathrm{HCl}, \mathrm{pH} 7.4)$ for $5 \mathrm{~min}$ each. Slides were dehydrated in absolute methanol for $10 \mathrm{~min}$ and left at room temperature to dry. The whole procedure was performed in dim light to minimize artefactual DNA damage. Just before visualization, each slide was stained with $50 \mu \mathrm{l}$ of ethidium bromide $(20 \mu \mathrm{g} / \mathrm{ml})$, rinsed with water and covered with a coverslip. The slides were observed at 10X magnification with a Leica Optiphase microscope equipped with an excitation filter of $515-560 \mathrm{~nm}$ and barrier filter of $590 \mathrm{~nm}$. A total of 100 cells were scored per tissue per animal (50 from each replicate slide). The nuclei were divided into five different categories on the basis of percentage of DNA in the tail using TriTek CometScore ${ }^{\mathrm{TM}}$ Freeware v1.5 software. The nuclei having $0-10 \%$ of tail DNA were categorized under 0 stage, $10-25 \%$ tail DNA under stage I, $25-50 \%$ tail DNA under stage II, $50-75 \%$ tail DNA under stage III and the nuclei having tail DNA $>75 \%$ were categorized under stage IV. The results are expressed as DNA damage index, calculated as $\# 0+\# 1+\# 2+\# 3+\# 4 /$ \# of cell scored where \# is the total number of nuclei counted.

\section{Micronucleus assay}

The in vivo micronucleus bone marrow test developed by Schmid [41] has been extensively used as a simple and sensitive short-term screening method for identification of genotoxic effects (chromosomal damage and aneuploidy) of natural and manmade chemicals.

Preparation and processing of bone marrow slides was performed as follows. Animals were anaesthetized by ether inhalation and sacrificed by cervical dislocation $24 \mathrm{~h}$ after last treatment; femur was dissected by cutting through pelvis and tibia, freed from adherent muscles. By gentle traction, the distal epiphyseal portion (knee cap) was removed and small hole was made with the help of 24 gauze needle. Bone marrow from the femur was aspirated into a $5 \mathrm{ml}$ glass centrifuge tube containing $5 \mathrm{ml}$ fetal calf serum (FCS) with the help of $0.5 \mathrm{ml}$ tuberculin syringe mounted with 26 gauze needle. The process of several aspirations and flushing were repeated to get maximum bone 
marrow cells into FCS. Bone marrow samples were centrifuged at $120 \mathrm{~g}$ for $5 \mathrm{~min}$, supernatant was removed and pellet was resuspended in a small volume of FCS. Bone marrow smears were prepared on clean microscopic glass slides. Four slides were prepared from each animal. Bone marrow slides were allowed to dry at room temperature overnight and stained with Giemsa according to the method of Gollapudi and Kamra [42]. Briefly the bone marrow slides were fixed in methanol for $5 \mathrm{~min}$, and were given two rinses by single distilled water. Slides were stained with Giemsa (1:6) solution for 10min and rinsed twice with distilled water to remove excess stain. Slides were air dried and cleared in xylene for $3 \mathrm{~min}$. On the next day slides were mounted with cover glass using Eukitt (BDH, UK) as mounting medium (Figure 1 and 2).

The slides were examined at $40 \mathrm{X}$ magnification for the selection of suitable region, where good spread, undamaged and better stained bone marrow cells were present. Selected slides were examined at 100X magnification under oil immersion for the frequencies of micronucleated polychromatic erythrocytes (MN-PCEs) in 1000 total PCEs from each slide/animal. Micronuclei in polychromatic erythrocytes were only accepted when round or crescent shaped and of dark bluish to violet in color. Ratio of polychromatic to normochromatic erythrocytes (P/N ratio) and percentage of polychromatic erythrocytes (\%PCE) was calculated by examining number of PCE which appeared violet to purple colored and normochromatic erythrocytes (NCE) which appeared pinkish in color in a total 200 erythrocytes from each animal and the $\mathrm{P} / \mathrm{N}$ ratio and $\% \mathrm{PCE}$ is calculated. Results are mean \pm SE of four set of observation.

\section{Statistical analyses}

For DNA damage, results are expressed as mean \pm S.E. of six sets of observations and for micronucleus assay results are mean \pm S.E. of four sets of observations taken on different days. Statistical analyses were performed using Sigma Stat Statistical software version 2.0. All the statistical analyses were performed using one-way analysis of variance with post hoc Bonferroni's multiple comparison test applied across the treatment groups. Significance was based on $\mathrm{P}$ value $<0.05$.

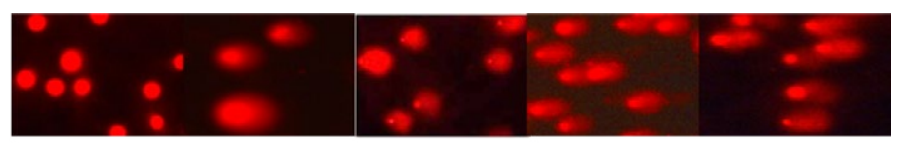

0 II

III

IV

Figure 1. Stages of DNA damage: The nuclei were divided into four different categories on the basis of percentage of DNA in tail. The nuclei having $0-10 \%$ of tail DNA werecategorized under 0 stage, the nuclei having tail DNA from $10-25 \%$ were categorized under stage I, $25-50 \%$ tail DNA containing nuclei were classified under stage II, 50-75\% tail DNA containing nuclei were marked under stage III and the nuclei having tail DNA $>75 \%$ were categorized under stage IV.

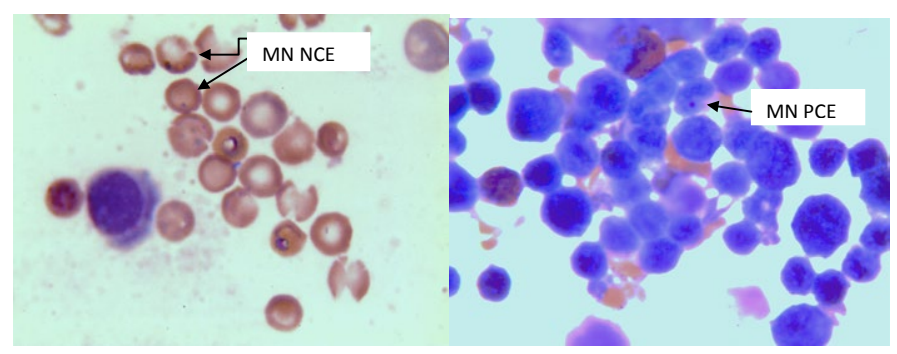

Figure 2. Micronuclei formation: Pesticide exposure leads to induction of micronuclei as shown in figure. MN NCE; micronucleated normochromatic erythrocytes, MN PCE; micronucleated polychromatic erythrocytes.

\section{Results}

\section{Effect of acute exposure of MCP and QNP on DNA strand breaks and protective effects melatonin}

To assess the potential of MCP and QNP either singly or in mixture to cause DNA damage in terms of strand breaks, single cell gel electrophoresis or comet assay was used. The rats were given acute as well as were chronic exposure of pesticides, liver, brain and lymphocytes isolated and alkaline and neutral single cell gel electrophoreses were performed to quantitate the DNA single and double strand breaks. The results of the present study showed that both MCP and QNP singly and in mixture caused significantly high levels of DNA damage in all the rat tissues examined namely, liver, brain and lymphocytes. The rats given $0.25 \mathrm{LD}_{50}$ equivalents of MCP and QNP dissolved in $0.4 \mathrm{ml}$ corn oil orally for two consecutive days, showed markedly high increase in the single strand breaks expressed as damage index (Table 1). The percent change was calculated by division of increase or decrease in the damage index by the control value so that the change could be calculated with respect to control and the extent of damage in the pesticide treated groups could be analysed. The increase observed in single strand damage index (SSDI) was 330\%, 350\% and 361\% in the liver, brain and lymphocytes, respectively, in the rats given MCP while QNP treated rats showed $312 \%, 334 \%$ and $315 \%$ increase in the liver, brain and lymphocytes, respectively, when compared with control. The mixture of both the pesticides also caused significantly high level of SSDI which was $310 \%, 303 \%$ and $308 \%$, in the liver, brain and lymphocytes, respectively (Table 1 ). These pesticides caused statistically significant increase in the DNA double strand breaks in the rat tissues. MCP exposure caused 283\%, 283\% and 292\% increase while QNP exposure caused $254 \%, 236 \%$ and $273 \%$ increase in the double strand damage index (DSDI) in the liver, brain and lymphocytes, respectively. When these pesticides are given together $214 \%, 142 \%$ and $241 \%$ increase was observed in the DSDI in the liver, brain and lymphocytes, respectively (Table 1).

Melatonin treatment showed protective effect against pesticides induced DNA single and double strand breaks in the liver, brain and lymphocytes of rats and the observed damage index showed statistically significative reduction. Intraperitoneal melatonin treatment $(5 \mathrm{mg} /$ $\mathrm{kg}$ body weight for two days) caused $2 \%, 5 \%$ and $5 \%$ reduction in the SSDI while $11 \%, 11 \%$ and $9 \%$ decrease in DSDI in the liver, brain and lymphocytes, respectively of control rats. Co-treatment of melatonin along with MCP, QNP and their mixture also caused significantly marled decrease in SSDI and DSDI in all the tissues of rats examined. Melatonin co-treatment with MCP caused $78 \%, 131 \%$ and $113 \%$ recovery in SSDI and $122 \%, 78 \%$ and $119 \%$ recovery in DSDI in the liver, brain and lymphocytes respectively, when compared with only pesticide treated group. Similarly $80 \%, 106 \%$ and $123 \%$ recovery in SSDI and $104 \%, 61 \%$ and $103 \%$ recovery in the DSDI in the liver, brain and lymphocytes, respectively, was observed in the group given co-treatment of melatonin and QNP when compared with only QNP treated group. The recovery observed in the SSDI ranged from $81 \%$ $157 \%$ and DSDI ranged from $66 \%$ - $151 \%$ in tissues of rats given combined treatment of MCP and QNP along with co treatment of melatonin when compared with corresponding melatonin untreated group (Table 1).

\section{Effect of chronic exposure of MCP and QNP on DNA single strand breaks and protective effects melatonin}

The chronic exposure of different doses of MCP and QNP either 
Table 1. DNA single strand breaks and double strand breaks induced by $0.25 \mathrm{LD}_{50}$ exposure of monocrotophos and quinalphos individually and in mixture, for two days, in rat tissues and lymphocytes.

\begin{tabular}{|c|c|c|c|c|c|c|c|c|}
\hline & Control & Control+MT & MCP & MCP+MT & QNP & QNP + MT & Mixture & Mixture + MT \\
\hline & \multicolumn{8}{|c|}{ Single Strand Breaks } \\
\hline Liver & $0.63 \pm 0.01$ & $0.62 \pm 0.01^{*}$ & $2.71 \pm 0.02^{* * * *}$ & $2.22 \pm 0.05^{* * * / \mathrm{d}^{* * * *}}$ & $2.60 \pm 0.03^{* * * *}$ & $2.09 \pm 0.03^{* * * / \mathrm{e}^{* * * *}}$ & $2.58 \pm 0.03^{* * *}$ & $1.98 \pm 0.04^{* * * / \mathrm{gh}^{* * * *}}$ \\
\hline Brain & $0.64 \pm 0.01$ & $0.61 \pm 0.01^{*}$ & $2.88 \pm 0.01^{* * * *}$ & $2.04 \pm 0.42^{* * * / \mathrm{cd}^{* * * *}}$ & $2.78 \pm 0.02^{* * * *}$ & $2.10 \pm 0.06^{* * * / / \mathrm{e}^{* * * *}}$ & $2.58 \pm 0.02^{* * * *}$ & $2.06 \pm 0.04^{* * * / \mathrm{gh}^{* * * *}}$ \\
\hline \multirow[t]{2}{*}{ Lymph. } & $0.59 \pm 0.01$ & $0.56 \pm 0.01^{* *}$ & $2.72 \pm 0.05^{* * * *}$ & $1.94 \pm 0.09^{* * * / \mathrm{dd}^{* * * *}}$ & $2.45 \pm 0.01^{* * *}$ & $1.72 \pm 0.01^{* * * / / \mathrm{e}^{* *}}$ & $2.41 \pm 0.05^{* * *}$ & $1.48 \pm 0.10^{* * * / \mathrm{gh}^{* * * *}}$ \\
\hline & \multicolumn{8}{|c|}{ Double Strand Breaks } \\
\hline Liver & $0.63 \pm 0.01$ & $0.56 \pm 0.01^{* *}$ & $2.41 \pm 0.05^{* * * *}$ & $1.64 \pm 0.04^{* * * / \mathrm{cd}^{* * * *}}$ & $2.23 \pm 0.02^{* * *}$ & $1.57 \pm 0.01^{* * * / / e} \mathrm{e}^{* * * *}$ & $1.98 \pm 0.03^{* * *}$ & $1.56 \pm 0.01^{* * * / \mathrm{gh}^{* * * *}}$ \\
\hline Brain & $0.64 \pm 0.01$ & $0.57 \pm 0.01^{* *}$ & $2.45 \pm 0.04^{* * * *}$ & $1.95 \pm 0.03^{* * * / \mathrm{dd}^{* * *}}$ & $2.15 \pm 0.07^{* * *}$ & $1.76 \pm 0.04^{* * * / \mathrm{e}^{* * *}}$ & $1.55 \pm 0.04^{* * *}$ & $1.50 \pm 0.05^{* * * / \mathrm{gh} \neq}$ \\
\hline Lymph. & $0.59 \pm 0.01$ & $0.54 \pm 0.01^{* *}$ & $2.31 \pm 0.02^{* * * *}$ & $1.61 \pm 0.05^{* * * / \mathrm{cd}^{* * *}}$ & $2.20 \pm 0.03^{* * * *}$ & $1.59 \pm 0.02^{* * * / / \mathrm{e}^{* * * *}}$ & $2.01 \pm 0.01^{* * * *}$ & $1.48 \pm 0.02^{* * * / \mathrm{gh}^{* * * *}}$ \\
\hline
\end{tabular}

Results of mean \pm S.E. of six set of observations taken on different days.

${ }^{\text {cd }}$ when $\mathrm{MCP}+\mathrm{MT}$ is compared with Control+MT.

${ }^{\text {ef }}$ when QNP+MT is compared with Control+MT.

${ }^{\mathrm{gh}}$ when MIX+MT is compared with Control+ MT.

The pesticide treated group was fed orally with $0.25 \mathrm{LD}_{50}$ dose of pesticide dissolved in $0.4 \mathrm{ml}$ of corn oil for two consecutive days. The

pesticide+melatonin treated group received a co- treatment of $5 \mathrm{mg} / \mathrm{kg}$ of melatonin intraperitoneally for two consecutive days. The control group received just $0.4 \mathrm{ml}$ of corn oil for two consecutive days. The control+melatonin group received just $5 \mathrm{mg} / \mathrm{Kg}$ of melatonin for two consecutive days.

${ }^{*} P<0.05,{ }^{*} P<0.01, * * * P<0.001$ and ${ }^{*} \mathrm{P}>0.5$ when compared with respective control.

Abbreviations: MT, Melatonin; MCP, Monocrotophos; QNP, Quinalphos; Lymp., Lymphocytes.

Table 2. DNA single strand breaks and double strand breaks induced by exposure of $\mathrm{LD}_{50}$ monocrotophos and quinalphos individually and in mixture, for sixty days, in rat tissues and lymphocytes.

\begin{tabular}{|c|c|c|c|c|c|c|c|c|}
\hline & Control & Control+MT & МCP & МCP+MT & QNP & QNP+MT & Mixture & Mixture+MT \\
\hline & \multicolumn{8}{|c|}{ Single Strand Breaks } \\
\hline Liver & $0.62 \pm 0.01$ & $0.59 \pm 0.01^{*}$ & $2.83 \pm 0.02^{* * * *}$ & $2.28 \pm 0.05^{* * * / \mathrm{cd}^{* * * *}}$ & $2.54 \pm 0.04^{* * * *}$ & $2.19 \pm 0.13^{* * * / / e^{f * * * *}}$ & $2.56 \pm 0.04^{* * * *}$ & $1.82 \pm 0.03^{* * * / \mathrm{gh}^{* * * *}}$ \\
\hline Brain & $0.66 \pm 0.01$ & $0.57 \pm 0.01^{* *}$ & $2.86 \pm 0.02^{* * *}$ & $1.92 \pm 0.52^{* / \mathrm{cd} \neq}$ & $2.57 \pm 0.05^{* * *}$ & $2.25 \pm 0.04^{* * * / \mathrm{e}^{* * *}}$ & $2.51 \pm 0.01^{* * * *}$ & $2.10 \pm 0.01^{* * * / \mathrm{gh}^{* * * *}}$ \\
\hline \multirow[t]{2}{*}{ Lymph. } & $0.62 \pm 0.01$ & $0.57 \pm 0.01^{* * *}$ & $2.18 \pm 0.07^{* * * *}$ & $1.58 \pm 0.02^{* * * / \mathrm{dd}^{* * * *}}$ & $1.62 \pm 0.05^{* * *}$ & $1.11 \pm 0.03^{* * * / \mathrm{e}^{* * * *}}$ & $1.26 \pm 0.01^{* * * *}$ & $0.97 \pm 0.02^{* * * / \mathrm{gh}^{* * * *}}$ \\
\hline & \multicolumn{8}{|c|}{ Double Strand Breaks } \\
\hline Liver & $0.63 \pm 0.01$ & $0.60 \pm 0.01^{*}$ & $2.62 \pm 0.02^{* * *}$ & $2.04 \pm 0.03^{* * * / \mathrm{cd}^{* * * *}}$ & $2.15 \pm 0.02^{* * *}$ & $2.06 \pm 0.13^{* * * * / \mathrm{e}^{*}}$ & $2.33 \pm 0.01^{* * *}$ & $1.84 \pm 0.03^{* * * / \mathrm{gh}^{* * * *}}$ \\
\hline Brain & $0.66 \pm 0.01$ & $0.61 \pm 0.01^{* *}$ & $2.74 \pm 0.04^{* * * *}$ & $2.26 \pm 0.06^{* * * / \mathrm{dd}^{* * * *}}$ & $2.22 \pm 0.06^{* * *}$ & $1.96 \pm 0.04^{* * * / e e^{* * *}}$ & $2.30 \pm 0.02^{* * * *}$ & $1.94 \pm 0.02^{* * * / \operatorname{gh}^{* * * *}}$ \\
\hline Lymph. & $0.56 \pm 0.01$ & $0.55 \pm 0.01^{\neq}$ & $1.23 \pm 0.04^{* * * *}$ & $0.84 \pm 0.07^{* * / c d^{* *}}$ & $0.98 \pm 0.02^{* * *}$ & $0.82 \pm 0.02^{* * * / \mathrm{e}^{* * *}}$ & $0.81 \pm 0.03^{* * * *}$ & $0.58 \pm 0.02^{\neq / \mathrm{gh}^{* * *}}$ \\
\hline
\end{tabular}

Results of mean \pm S.E. of six set of observations taken on different days.

${ }^{\mathrm{cd}}$ when $\mathrm{MCP}+\mathrm{MT}$ is compared with Control+ MT.

${ }^{\text {ef }}$ when QNP+MT is compared with Control+MT.

${ }^{\mathrm{gh}}$ when MIX+MT is compared with Control+MT.

The pesticide treated group was fed orally with $\mathrm{LD}_{50}$ dose of pesticide dissolved in $0.4 \mathrm{ml}$ of corn oil for sixty days. The pesticide+melatonin treated group received a co- treatment of $5 \mathrm{mg} /$ $\mathrm{kg}$ of melatonin intraperitonieally for sixty days. The control group received just $0.4 \mathrm{ml}$ of corn oil for sixty days.

The control+melatonin group received just $5 \mathrm{mg} / \mathrm{Kg}$ of melatonin for sixty days.

${ }^{*} P<0.05,{ }^{*} P<0.01,{ }^{* * *} P<0.001$ and ${ }^{*} \mathrm{P}>0.5$ when compared with respective control.

Abbreviations: MT, Melatonin; MCP, Monocrotophos; QNP, Quinalphos; Lymp., Lymphocytes.

singly or in mixture to rats caused extensive dose-dependent DNA damage in rat tissues and lymphocytes measured by comet assay. Different groups of rats were given $\mathrm{LD}_{50}$ and $2 \mathrm{LD}_{50}$ equivalent of $\mathrm{MCP}$, QNP and their mixture in equal doses for 60 days and single and double strand DNA breaks were measured in the liver, brain and lymphocytes along with respective controls. The results showed that $\mathrm{LD}_{50}$ equivalent of MCP exposure caused $356 \%, 333 \%$ and $252 \%$ increase in SSDI while doubling the dose caused $415 \%, 406 \%$ and $268 \%$ increase in the SSDI in the liver, brain and lymphocytes, respectively, when compared with respective controls. The magnitude of DSDI observed was 316\%, 315\% and $120 \%$ in the $\mathrm{LD}_{50}$ treated group while $380 \%, 353 \%$ and $247 \%$ increase in DSDI was observed in the liver, brain and lymphocytes, respectively, of $2 \mathrm{LD}_{50}$ equivalents of MCP treated rats when compared with control (Table 2 and 3). The increase in SSDI observed in $\mathrm{LD}_{50}$ equivalents of QNP treated rats ranged from $161 \%$ to $285 \%$ while doubling the dose of QNP caused statistically significant increase in SSDI in the range of $209 \%$ to $361 \%$ in the liver, brain and lymphocytes of rats when compared with respective controls. The DSDI was increased by $241 \%$, $236 \%$ and $75 \%$ in the group receiving $\mathrm{LD}_{50}$ equivalents of QNP and $316 \%, 352 \%$ and $187 \%$ in the liver, brain and lymphocytes, respectively, of rats receiving $2 \mathrm{LD}_{50}$ equivalents of QNP in 60 days divided in 60 equal doses when comprised with respective controls (Table 2 and 3 ). The rats receiving combined exposure of $\mathrm{MCP}+\mathrm{QNP}$ showed statistically significant increase of 313\%, 280\% 167\% in the SSDI when given $\mathrm{LD}_{50}$ equivalent of pesticide mixture while doubling the dose caused $316 \%, 296 \%$ and $194 \%$ increase in the SSDI in the liver, brain and lymphocytes, respectively, when compared with tissues of control rats. The highly significant increase $(\mathrm{P}=0.001)$ in DSDI ranged from $45 \%$ to $270 \%$ and $147 \%$ to $316 \%$ in the tissues of rats receiving $\mathrm{LD}_{50}$ and $2 \mathrm{LD}_{50}$ equivalents of pesticide mixture, respectively, when compared with respective controls.

Melatonin co-treatment showed protective effects against pesticides induced DNA damage and the magnitude of DNA single strand breaks and double strand breaks were significantly reduced 
Table 3. DNA single strand breaks and double strand breaks induced by exposure of $2 \mathrm{LD}_{50}$ monocrotophos and quinalphos individually and in mixture, for sixty days, in rat tissues and lymphocytes.

\begin{tabular}{|c|c|c|c|c|c|c|c|c|}
\hline & Control & Control +MT & МCP & MCP+MT & QNP & QNP+MT & Mixture & Mixture+ MT \\
\hline & \multicolumn{8}{|c|}{ Single Strand Breaks } \\
\hline Liver & $0.68 \pm 0.01$ & $0.62 \pm 0.01^{* *}$ & $2.50 \pm 0.04^{* * *}$ & $1.74 \pm 0.04^{* * * / \mathrm{dd}^{* * * *}}$ & $2.10 \pm 0.06^{* * * *}$ & $1.48 \pm 0.04^{* * * / \mathrm{e}^{* * * *}}$ & $1.53 \pm 0.02^{* * * *}$ & $1.17 \pm 0.06^{* * * / \mathrm{gh}^{* * * *}}$ \\
\hline Brain & $0.66 \pm 0.01$ & $0.60 \pm 0.01^{*}$ & $3.34 \pm 0.05^{* * *}$ & $2.74 \pm 0.03^{* * * / \mathrm{cd} * * *}$ & $3.04 \pm 0.03^{* * * *}$ & $2.68 \pm 0.01^{* * * / / \mathrm{e}^{\mathrm{f} * * *}}$ & $2.61 \pm 0.02^{* * * *}$ & $1.69 \pm 0.08 \mathrm{~s}^{* * * / g \mathrm{gh}^{* * * *}}$ \\
\hline \multirow[t]{2}{*}{ Lymph. } & $0.68 \pm 0.01$ & $0.60 \pm 0.01^{* * *}$ & $2.50 \pm 0.04^{* * *}$ & $1.74 \pm 0.02^{* * * / \mathrm{d}^{* * * *}}$ & $2.10 \pm 0.06^{* * *}$ & $1.48 \pm 0.04^{* * * / \mathrm{e}^{* * * *}}$ & $1.50 \pm 0.02^{* * * *}$ & $1.17 \pm 0.06^{* * * / \mathrm{gh}^{* * * *}}$ \\
\hline & \multicolumn{8}{|c|}{ Double Strand Breaks } \\
\hline Liver & $0.64 \pm 0.01$ & $0.61 \pm 0.01^{\neq}$ & $3.07 \pm 0.04^{* * *}$ & $1.72 \pm 0.08^{* * * / \mathrm{d}^{* * * *}}$ & $2.66 \pm 0.06^{* * *}$ & $1.59 \pm 0.01^{* * * /} / \mathrm{e}^{* * * *}$ & $2.61 \pm 0.05^{* * * *}$ & $1.32 \pm 0.03^{* * * / \mathrm{gh}^{* * *}}$ \\
\hline Brain & $0.64 \pm 0.01$ & $0.63 \pm 0.01^{\neq}$ & $2.90 \pm 0.05^{* * *}$ & $1.63 \pm 0.04^{* * * / \mathrm{dd}^{* * * *}}$ & $2.89 \pm 0.11^{* * * *}$ & $1.47 \pm 0.03^{* * * / / \mathrm{e}^{* * * *}}$ & $2.66 \pm 0.05^{* * * *}$ & $1.92 \pm 0.05^{* * * / \mathrm{gh}^{* * * *}}$ \\
\hline Lymph. & $0.60 \pm 0.01$ & $0.58 \pm 0.01^{\neq}$ & $2.08 \pm 0.04^{* * *}$ & $1.64 \pm 0.07^{* * * / \mathrm{cd}^{* * * *}}$ & $1.72 \pm 0.04^{* * * *}$ & $1.47 \pm 0.02^{* * * / / \mathrm{e}^{\mathrm{f} * * *}}$ & $1.48 \pm 0.04^{* * * *}$ & $1.25 \pm 0.03^{* * * / g h^{* * *}}$ \\
\hline
\end{tabular}

Results of mean \pm S.E. of six set of observations taken on different days.

${ }^{\mathrm{cd}}$ when $\mathrm{MCP}+\mathrm{MT}$ is compared with Control+MT.

${ }^{\text {ef }}$ when QNP+MT is compared with Control+MT.

${ }^{\mathrm{gh}}$ when MIX+MT is compared with Control+MT.

The pesticide treated group was fed orally with $2 \mathrm{LD}_{50}$ dose of pesticide dissolved in $0.4 \mathrm{ml}$ of corn oil for sixty days. The pesticide + melatonin treated group received a co- treatment of $5 \mathrm{mg} / \mathrm{kg}$ of melatonin intraperitonieally for sixty days. The control group received just $0.4 \mathrm{ml}$ of corn oil for sixty days. The control $+\mathrm{melatonin}$ group received just $5 \mathrm{mg} / \mathrm{Kg}$ of melatonin for sixty days.

${ }^{*} P<0.05,{ }^{* *} P<0.01,{ }^{* * *} P<0.001$ and ${ }^{\#} \mathrm{P}>0.5$ when compared with respective control.

Abbreviations: MT, Melatonin; MCP, Monocrotophos; QNP, Quinalphos; Lymp., Lymphocytes.

Table 4. Micronuclei induced by $0.25 \mathrm{LD}_{50}$ exposure of monocrotophos and quinalphos individually and in mixture, for two days, in rat bone marrow.

\begin{tabular}{|l|l|l|l|l|l|l|l|l|l|}
\hline & Control & Control+MT & CPM & MCP & MCP+MT & QNP & QNP +MT & Mixture & Mixture +MT \\
\hline MN PCE & $0.32 \pm 0.05$ & $0.22 \pm 0.05^{\#}$ & $3.00 \pm 0.09^{* * *}$ & $2.02 \pm 0.24^{* * *}$ & $1.70 \pm 0.24^{* * *}$ & $1.55 \pm 0.27^{* * *}$ & $0.95 \pm 0.17^{* * *}$ & $1.05 \pm 0.06^{* * *}$ & $0.65 \pm 0.06^{* * *}$ \\
\hline P/N ratio & $1.31 \pm 0.02$ & $1.33 \pm 0.02^{\#}$ & $0.70 \pm 0.01^{* * *}$ & $0.75 \pm 0.01^{* * *}$ & $0.83 \pm 0.01^{* * *}$ & $0.79 \pm 0.01^{* * *}$ & $0.88 \pm 0.01^{* * *}$ & $0.95 \pm 0.01^{* * *}$ & $0.91 \pm 0.02^{* * *}$ \\
\hline \%PCE & $56.75 \pm 0.32$ & $57.12 \pm 0.31^{\#}$ & $41.12 \pm 0.43^{* * *}$ & $44.12 \pm 0.59^{* * *}$ & $45.38 \pm 0.43^{* * *}$ & $44.25 \pm 0.43^{* * *}$ & $46.75 \pm 0.32^{* * *}$ & $47.75 \pm 0.52^{* * *}$ & $48.75 \pm 0.32^{* * *}$ \\
\hline
\end{tabular}

Results of mean \pm S.E. of four set of observations taken on different days.

The pesticide treated group was fed orally with $0.25 \mathrm{LD}_{50}$ dose of pesticide dissolved in $0.4 \mathrm{ml}$ of corn oil for two consecutive days.

The pesticide+melatonin treated group received a co- treatment of $5 \mathrm{mg} / \mathrm{kg}$ of melatonin intraperitoneally for two consecutive days.

The cyclophosphamide was used a positive control and the group received $40 \mathrm{mg} / \mathrm{Kg}$ of cyclophosphamide orally for two consecutive days. The control group received just $0.4 \mathrm{ml}$ of corn oil for two consecutive days. The control+melatonin group received just $5 \mathrm{mg} / \mathrm{Kg}$ of melatonin for two consecutive days.

$* P<0.05,{ }^{*} P<0.01, * * * P<0.001$ and ${ }^{*} \mathrm{P}>0.5$ when compared with respective control.

Abbreviations: MT, Melatonin; MCP, Monocrotophos; QNP, Quinalphos; CPM, Cyclophosphamide; MN PCE, Micronucleated polychromatic erythrocytes; P/N, Polychromatic erythrocytes/ Normochromatic erythrocytes; \%PCE, Percentage of polychromatic erythrocytes.

in tissues of rats of these groups when compared with only pesticide treated rats. Melatonin treatment to control rats caused decrease in the SSDI in range of $5 \%$ to $14 \%$ and in the DSDI in the range of $2 \%$ to $8 \%$ in the tissues of rats when compared with vehicle treated group (Table 2 and 3). When the melatonin was given with $\mathrm{LD}_{50}$ equivalents of $\mathrm{MCP}$ for 60 days $88 \%, 142 \%$ and $97 \%$ decrease in the SSDI and $92 \%, 73 \%$ and $70 \%$ decrease in the DSDI was observed in the liver, brain and lymphocytes of rats, respectively, when compared with control (Table 2). Co-treatment of QNP and melatonin resulted in $32 \%, 48 \%$ and $82 \%$ decrease in the SSDI and 14\%, 39\% and 29\% decrease in the DSDI, in the liver, brain and lymphocytes of rats, respectively, when compared with melatonin untreated group receiving $\mathrm{LD}_{50}$ equivalents of QNP. The group of rats receiving co-treatment of melatonin with mixture of MCP and QNP, showed $119 \%, 62 \%$ and $111 \%$ decrease in the SSDI and $78 \%, 55 \%$ and $41 \%$ decrease in the DSDI in the liver, brain and lymphocytes, respectively, when compared with tissues of melatonin untreated rats (Table 2). The rats receiving melatonin co-treatment along with $2 \mathrm{LD}_{50}$ equivalents of MCP showed $112 \%, 61 \%$ and $112 \%$ decrease in SSDI and $102 \%, 151 \%$ and $74 \%$ decrease in DSDI in the liver, brain and lymphocytes of rats, respectively, when compared with melatonin untreated-MCP treated group (Table 3). Melatonin cotreatment with QNP resulted in the $94 \%, 55 \%$ and $47 \%$ decrease in the SSDI and $105 \%, 144 \%$ and $42 \%$ decrease in the DSDI in the liver, brain and lymphocytes of rats, respectively when compared with respective tissues of melatonin untreated group (Table 3). Combined exposure of
$2 \mathrm{LD}_{50}$ equivalents of $\mathrm{MCP}+\mathrm{QNP}$ along with melatonin co-treatment decreased the SSDI by $97 \%, 64 \%$ and $92 \%$ and DSDI by $124 \%, 116 \%$ and $39 \%$ in the liver, brain and lymphocytes of rats compared with respective tissues of melatonin untreated group.

\section{Effect of acute exposure of MCP and QNP on micronuclei induction in polychromatic erythrocytes and protective effects of melatonin}

To further confirm the genotoxic potential of the selected pesticides, in vivo bone marrow micronucleus test was performed as simple and sensitive short-term screening method for identification of genotoxic effects (chromosomal damage and aneuploidy). The acute exposure of $0.25 \mathrm{LD}_{50}$ equivalent of MCP and QNP singly and in combination for two consecutive days caused a significant increase in the micronucleated polychromatic erythrocytes (MN PCE) and concomitant decrease in the percentage of PCE (\%PCE) and ratio of polychromatic/normochromatic erythrocytes (P/N ratio) (Table 4). Cyclophosphamide (CPM) was taken as the positive control and was given to the rats at a dose of $40 \mathrm{mg} / \mathrm{kg}$ body weight orally for two consecutive days. Results showed that acute exposure of MCP, QNP singly and in mixture caused 6.3 folds, 4.8 folds and 3.3 folds increase in the MN PCE while P/N ratio was decreased by 1.74 folds, 1.7 folds and 1.4 folds, respectively, and \%PCE were decreased by $12.63 \%$, $12.5 \%$ and $9 \%$ respectively, when compared with control (Table 4). The increase observed in MN PCE in CPM treated group was 9.4 
folds while 1.9 folds decrease in the $\mathrm{P} / \mathrm{N}$ ratio and $15.63 \%$ decrease in the \%PCE was observed in this group when compared with control. Melatonin co-treatment offered protection against MCP, QNP and mixture induced changes in the MN PCE, P/N ratio and \%PCE. The increase in MN PCE was 5.32 folds in MCP+MT treated group, 2.9 folds in QNP+MT treated group and 2.03 folds in mixture+MT treated group. The decrease in $\mathrm{P} / \mathrm{N}$ ration was 1.6 folds, 1.5 folds and 1.44 folds while decrease in \% $\mathrm{PCE}$ was $11.37 \%, 10 \%$ and $8 \%$ in the group receiving $\mathrm{MCP}+\mathrm{MT}$, $\mathrm{QNP}+\mathrm{MT}$ and mixture $+\mathrm{MT}$, respectively, when compared with the control group (Table 4).

\section{Effect of chronic exposure of MCP and QNP on micronuclei induction in polychromatic erythrocytes and protective effects of melatonin}

Chronic exposure of $\mathrm{LD}_{50}$ and $2 \mathrm{LD}_{50}$ equivalents of MCP and QNP singly and in mixture caused dose-dependent changes in the MN PCE, $\mathrm{P} / \mathrm{N}$ ratio and \%PCE. The increase in MN PCE was 6.8-, 5.65- and 3.28 folds in the group receiving $\mathrm{LD}_{50}$ equivalents of $\mathrm{MCP}, \mathrm{QNP}$ and their mixture, respectively, while 7.57-, 6.28- and 3.94- folds increase was observed in the group receiving double the dose of MCP, QNP and their mixture, respectively (Table 5 and 6). The decrease in $\mathrm{P} / \mathrm{N}$ ratio was 1.6-, 1.76- and 1.58- folds on treatment of $\mathrm{LD}_{50}$ equivalents and 1.79-, 1.76- and 1.6- folds on treatment of $2 \mathrm{LD}_{50}$ equivalents of $\mathrm{MCP}, \mathrm{QNP}$ and their mixture, respectively, when compared with control. The decrease in \%PCE was $11.75 \%, 12.37 \%$ and $11.37 \%$ on treatment of $\mathrm{LD}_{50}$ equivalents and $14 \%, 13.5 \%$ and $11.5 \%$ on treatment of $2 \mathrm{LD}_{50}$ equivalents of $\mathrm{MCP}, \mathrm{QNP}$ and their mixture, respectively, when compared with control. $\mathrm{LD}_{50}$ and $2 \mathrm{LD}_{50}$ equivalents of $\mathrm{CPM}$ treatment caused 8.71- and 8.8- increase in MN PCE, 1.91- and 1.98folds decrease in $\mathrm{P} / \mathrm{N}$ ration and $16.25 \%$ and $17.37 \%$ increase in PCE, respectively, when compared with the control group (Table 5 and 6).
Melatonin co-treatment caused protection against pesticide induced changes in the levels of MN PCE, P/N ration and \% PCE. Only 3.66, 2.85- and 2.14- folds increase was observed in the group receiving $\mathrm{LD}_{50}$ equivalents of MCP, QNP and their mixture along with melatonin while 4.77-, 5- and 2.22- folds increase was observed in the group receiving $2 \mathrm{LD}_{50}$ equivalents of $\mathrm{MCP}, \mathrm{QNP}$ and their mixture along with melatonin, respectively. The decrease in $\mathrm{P} / \mathrm{N}$ ratio observed was 1.5-, 1.15- and 1.12- folds in the group receiving $\mathrm{LD}_{50}$ equivalent of $\mathrm{MCP}+\mathrm{MT}, \mathrm{QNP}+\mathrm{MT}$ and mixture $+\mathrm{MT}$, respectively, while 1.64-, 1.6and 1.5- folds in the group receiving $2 \mathrm{LD}_{50}$ equivalent of $\mathrm{MCP}+\mathrm{MT}$, $\mathrm{QNP}+\mathrm{MT}$ and mixture+MT, respectively, when compared with respective control (Table 5 and 6). The decrease in \%PCE was $10.5 \%$, $4.5 \%$ and $3.13 \%$ in the group receiving $\mathrm{LD}_{50}$ equivalent of $\mathrm{MCP}+\mathrm{MT}$, $\mathrm{QNP}+\mathrm{MT}$ and mixture $+\mathrm{MT}$, respectively, while doubling the dose of pesticides caused $12.87 \%, 11.25 \%$ and $10 \%$ decrease in PCE.

\section{Discussion}

Pesticides are the chemical substances extensively used in agriculture and public health programs to control and eliminate unwanted pests and associated diseases. However the increased use of these compounds has caused adverse health effects and thus necessitates precise toxicological tests and risk assessments. DNA alterations are known to be indicators of early damage in the affected organisms; consequently identifying the genotoxic potential of these xenobiotics has been an effective and beneficial strategy for risk assessment. Although pesticides have been widely analyzed for their ability to cause DNA damage and subsequent mutagenicity, carcinogenicity and other adverse health effects, the researches on few pesticides are still lacking [43-45]. Quinalphos (QNP) and monocrotophos (MCP) are the commonly used OP pesticides, known to cause toxicity to humans and various other non-target organisms [46,47]. There are

Table 5. Micronuclei induced by LD50 exposure of monocrotophos and quinalphos individually and in mixture, for sixty days, in rat bone marrow.

\begin{tabular}{|c|c|c|c|c|c|c|c|c|c|}
\hline & Control & Control+MT & CPM & MCP & MCP+MT & QNP & QNP + MT & Mixture & Mixture +MT \\
\hline MN PCE & $0.35 \pm 0.03$ & $0.27 \pm 0.05 \#$ & $3.05 \pm 0.06^{* * *}$ & $2.38 \pm 0.19^{* * *}$ & $1.28 \pm 0.11 * *$ & $1.98 \pm 0.17 * * *$ & $1.00 \pm 0.04 * * *$ & $1.15 \pm 0.21 * *$ & $0.75 \pm 0.03 * * *$ \\
\hline $\mathrm{P} / \mathrm{N}$ ratio & $1.30 \pm 0.02$ & $1.33 \pm 0.02 \#$ & $0.68 \pm 0.01 * * *$ & $0.82 \pm 0.04 * * *$ & $0.86 \pm 0.04 * * *$ & $0.80 \pm 0.03 * * *$ & $1.16 \pm 0.16^{* * *}$ & $0.83 \pm 0.03 * * *$ & $1.16 \pm 0.04 * * *$ \\
\hline$\% \mathrm{PCE}$ & $56.75 \pm 0.32$ & $57.12 \pm 0.43 \#$ & $40.50 \pm 0.20^{* * *}$ & $45.00 \pm 1.10^{* * *}$ & $46.25 \pm 1.20 * * *$ & $44.38 \pm 0.90 * * *$ & $52.25 \pm 3.26^{* * *}$ & $45.38 \pm 0.77 * * *$ & $53.62 \pm 0.72 * * *$ \\
\hline
\end{tabular}

Results of mean \pm S.E. of four set of observations taken on different days.

The pesticide treated group was fed orally with LD50 dose of pesticide dissolved in $0.4 \mathrm{ml}$ of corn oil for sixty days. The pesticide+melatonin treated group received a co- treatment of $5 \mathrm{mg} / \mathrm{kg}$ of melatonin intraperitonieally for sixty days.

The cyclophosphamide was used as a positive control and the group received $10 \mathrm{mg} / \mathrm{Kg}$ of cyclophosphamide orally for sixty days. The control group received just $0.4 \mathrm{ml}$ of corn oil for sixty days. The control+melatonin group received just $5 \mathrm{mg} / \mathrm{Kg}$ of melatonin for sixty days.

$* \mathrm{P}<0.05, * * \mathrm{P}<0.01, * * * \mathrm{P}<0.001$ and $\# \mathrm{P}>0.5$ when compared with respective control.

Abbreviations: MT,Melatonin; MCP,Monocrotophos; QNP,Quinalphos; CPM, Cyclophosphamide; MN PCE, Micronucleated polychromatic erythrocytes; P/N ,Polychromatic erythrocytes/ Normochromatic erythrocytes; \%PCE, Percentage of polychromatic erythrocytes.

Table 6. Micronuclei induced by 2LD50 exposure of monocrotophos and quinalphos individually and in mixture, for sixty days, in rat bone marrow.

\begin{tabular}{|c|c|c|c|c|c|c|c|c|c|}
\hline & Control & Control+MT & CPM & MCP & MCP+MT & QNP & QNP + MT & Mixture & Mixture +MT \\
\hline MN PCE & $0.35 \pm 0.03$ & $0.12 \pm 0.03 \#$ & $3.08 \pm 0.07 * * *$ & $2.30 \pm 0.15^{* * *}$ & $1.67 \pm 0.11 * * *$ & $2.20 \pm 0.09 * * *$ & $1.75 \pm 0.06^{* * *}$ & $1.38 \pm 0.09 * * *$ & $0.78 \pm 0.14 *$ \\
\hline $\mathrm{P} / \mathrm{N}$ ratio & $1.31 \pm 0.02$ & $1.33 \pm 0.02 \#$ & $0.66 \pm 0.01 * * *$ & $0.73 \pm 0.01 * * *$ & $0.80 \pm 0.03 * * *$ & $0.74 \pm 0.01 * * *$ & $0.82 \pm 0.01 * * *$ & $0.81 \pm 0.01 * * *$ & $0.86 \pm 0.01 * * *$ \\
\hline$\% \mathrm{PCE}$ & $56.25 \pm 0.32$ & $56.50 \pm 0.35 \#$ & $38.88 \pm 0.43^{* * *}$ & $42.25 \pm 0.32 * * *$ & $43.38 \pm 1.46^{* * *}$ & $42.75 \pm 0.32 * * *$ & $45.00 \pm 0.35^{* * *}$ & $44.75 \pm 0.32 * * *$ & $46.25 \pm 0.32 * * *$ \\
\hline
\end{tabular}

Results of mean \pm S.E. of four set of observations taken on different days.

The pesticide treated group was fed orally with LD50 dose of pesticide dissolved in $0.4 \mathrm{ml}$ of corn oil for sixty days. The pesticide + melatonin treated group received a co- treatment of $5 \mathrm{mg} / \mathrm{kg}$ of melatonin intraperitonieally for sixty days.

The cyclophosphamide was used as a positive control and the group received $10 \mathrm{mg} / \mathrm{Kg}$ of cyclophosphamide orally for sixty days. The control group received just $0.4 \mathrm{ml}$ of corn oil for sixty days. The control+melatonin group received just $5 \mathrm{mg} / \mathrm{Kg}$ of melatonin for sixty days.

$* \mathrm{P}<0.05,{ }^{*} \mathrm{P}<0.01, * * * \mathrm{P}<0.001$ and $\# \mathrm{P}>0.5$ when compared with respective control.

Abbreviations: MT, Melatonin; MCP, Monocrotophos; QNP, Quinalphos; CPM, Cyclophosphamide; MN PCE, Micronucleated polychromatic erythrocytes; P/N, Polychromatic erythrocytes/Normochromatic erythrocytes; \%PCE, Percentage of polychromatic erythrocytes. 
very few reports on the genotoxicity of QNP and no report is available in literature on the level of DNA damage when the combined exposure of these pesticides is given. This study was undertaken to evaluate the in vivo genotoxicity of these pesticides when given singly or in mixture by using two commonly used tests, the single cell gel electrophoresis/ comet assay and the micronucleus $[\mathrm{MN}]$ assay. Comet assay is one of the most sensitive and rapid techniques, having wide range of applications in the assessment of different types of DNA damage and repair and has been widely used in the field of genetic toxicology and environmental biomonitoring, dietary intervention studies and cancer $[31,48]$. It provides considerable advantages over other conventional cytogenetic methods used to detect DNA damage, because for comet assay, the cells need not to be mitotically active. The other test i.e. in vivo $\mathrm{MN}$ assay, due to its simplicity, sensitivity and ease of detection, is the most prevalent biomonitoring test of measuring chromosomal defects induced by genotoxic agents. A variety of clastogenic and aneugenic genotoxins have been tested in different cells and tissues, using the MN test as one of the end points [49]. In the present study, $\mathrm{MN}$ test is used to confirm the chromosomal damage induced by the selected pesticides. The MN test is also used to assess the mutagenicity of toxins.

Results of the present study showed that the acute as well as chronic exposure of both MCP and QNP, singly and in combination, induced single and double strand breaks in DNA, as evident from the increased DNA damage index. The significantly high increase in the damage index on exposure with MCP, QNP and their mixture was observed in the liver, brain and lymphocytes of rats given acute or chronic exposures. The number of damaged nuclei of Type 1, 2, 3 and 4 were significantly increased in both the tissues and lymphocytes resulting in many fold increase in damage index. Different levels of DNA damage was observed in the liver, brain and lymphocytes of rats receiving MCP, QNP and their mixture measured by alkaline and neutral comet assay with brain showing highest levels of damage followed by liver and lymphocytes. Oxidative stress is involved in pathophysiology of several toxic compounds. Oxidative damage to DNA is the most common type of DNA damage observed in exposure with number of toxicants and diseases. Organophosphate pesticide exposure leads to oxidative stress and the role of reactive oxygen species (ROS) in production of DNA single and double strand breaks is well known [50]. The OP pesticides have been widely studied for their ability to cause DNA damage in different organisms. Cypermethrin, a pyrethroid pesticide is known to induce dose- dependent increase in DNA damage in the rat liver cells [51]. Dimethoate, causes DNA damage in mouse bone marrow cells [52], the oral exposure of chlorpyrifos, has been tested for its ability to induce in vivo genotoxicity in blood lymphocytes and different tissues of male and female Wistar rats in a dose dependent manner $[7,9,10,53]$. Similarly, other OP pesticides such as methyl parathion, malathion, phorate, fenthion and terbufos have been found to be genotoxic $[9,10,13,54]$. The genotoxicity of malathion in the sperms was confirmed using chromosome aberration, sister chromatid exchange (SCE) and abnormality assays. The combination of different pesticides is also very deleterious to the integrity of the DNA. Three equimolar pesticides viz., endosulfan, carbofuran and monocrotophos were investigated for their capacity to damage cultured human peripheral blood lymphocytes [55]. Not only in model organisms, the OPs have also been found to be genotoxic in human beings. The genotoxicity tests conducted in the pesticide applicators were found to be positive in majority of subjects belonging to different groups [56].

The OP pesticides are known to produce oxidative stress by inhibiting enzymatic and non-enzymatic antioxidants [2]. Depletion of cellular glutathione (GSH), an extremely important non-enzymatic antioxidant, below a critical level prevents the conjugation of xenobiotics to GSH and enables them to freely combine covalently with various cellular macromolecules including DNA, RNA and cellular proteins, resulting in cellular damage. Brain is particularly susceptible to oxidative injuries due to its high content of polyunsaturated fatty acids, low levels of antioxidant defense and consumption of relatively large amounts of oxygen [57]. Because of these structural and physiological features, highest level of DNA damage was observed in the brain in the present study. While MCP being more genotoxic than QNP, the chronic exposure caused higher damage than the acute exposure. Both MCP and QNP are known to produce oxidative stress due to alterations in the levels of enzymatic as well as non-enzymatic antioxidants leading to disturbance in the redox status in rat tissues [58]. As enhanced ROS level is the main cause of DNA strand scission, the oxidative stress generated by MCP and QNP may be responsible for the DNA damage observed in the present study.

The natural dietary antioxidants, vitamin $\mathrm{C}$ and $\mathrm{E}$, show protective effects against the toxicity induced by pesticides [2]. Vitamins $\mathrm{C}$ and E showed protective effects at different doses of carbofuran in in vitro toxicity studies [59]; against the toxicity of dichlorvos in human erythrocytes [53] and against chlorpyrifos in rats [60]. Melatonin, a hormone secreted from the pineal gland, has been extensively studied for its antioxidant properties. It has the ability to upregulate and downregulate the activity of various antioxidant enzymes and it also enhances the action of antioxidants such as Trolox and ascorbate [24]. Melatonin showed protective effects against the toxicity caused due to malathion in Wistar rats [27]. It is also known to possess protective effects against the genotoxicity of OP pesticides such as diazinon [61].

The study clearly demonstrates that both acute and chronic exposure of MCP and QNP are highly damaging to DNA with low level, long-term exposure shows more damaging effects. MCP is more toxic than QNP. The highest damage index and frequency of MN PCE in all the exposed groups was found in the brain, followed by liver and lymphocytes, showing the highest susceptibility of this tissue towards the pesticide toxicity. The study also shows that when these pesticides are given together, they do not potentiate the action of each other. The protective effects of melatonin are clearly observed at all the doses. Since, melatonin is known for its antioxidant properties it exhibited the possibility of being used as a therapeutic/prophylactic agent against the genotoxicity of OPs, which is confirmed in this study. The selected pesticides showed genotoxic potential and see to be clastogenic as evident from results of MN test. Since these pesticides are widely used in agriculture and health care programs, caution should be exercised in their handling as prolonged exposure may lead to adverse health effects including cancer, organ damage or other degenerative disorders.

\section{Acknowledgement}

The financial support of Department of Science and Technology, New Delhi, India, in the form of FIST grant to the school and in the form of individual research project to Nalini Srivastava, is thankfully acknowledged.

\section{References}

1. WHO 2008: The Global Burden of Disease-2004 update, Geneva.

2. Lukaszewicz-Hussain A (2010) Role of oxidative stress in organophosphate insecticides toxicity- Short review. Pestic Biochem Physiol. 98: 145-150.

3. Kazemi M, Tahmasbi AM, Valizadeh R, Naserian AA, Soni A, et al. (2012) Importance 
and toxicological effects of organophosphorous pesticides: A comprehensive review. BRJASR. 1: 43-57.

4. Olinski R, Gackowski D, Foksinski M, Rozalski R, Roszkowski K, et al. (2002) Oxidative DNA damage: assessment of the role in carcinogenesis, atherosclerosis, and acquired immunodeficiency syndrome. Free Radic Biol Med 33: 192-200. [Crossref]

5. Muniz JF, McCauley L, Scherer J, Lasarev M, Koshy M, et al. (2008) Biomarkers of oxidative stress and DNA damage in agricultural workers: a pilot study. Toxicol Appl Pharmacol. 227: 97-107. [Crossref]

6. Cooke MS, Evans MD, Dizdaroglu M, Lunec J (2003) Oxidative DNA damage: mechanisms, mutation, and disease. FASEB J 17: 1195-1214. [Crossref]

7. Mehta A, Verma RS, Srivastava N (2008) Chlorpyrifos-induced DNA damage in rat liver and brain. Environ Mol Mutagen 49: 426-433. [Crossref]

8. Yaduvanshi SK, Ojha A, Pant SC, Lomash V, Srivastava N (2010) Monocrotophos induced lipid peroxidation and oxidative DNA damage in rat tissues. Pestic Biochem Physiol. 97: 214-222.

9. Ojha A, Yaduvanshi SK, Pant SC, Lomash V, Srivastava, N (2013) Evaluation of DNA damage and cytotoxicity induced by three commonly used organophosphate pesticides individually and in mixture, in rat tissues. Environ Toxicol. 28: 543-552. [Crossref]

10. Ojha A, Srivastava N2 (2014) In vitro studies on organophosphate pesticides induced oxidative DNA damage in rat lymphocytes. Mutat Res Genet Toxicol Environ Mutagen 761: 10-17. [Crossref]

11. Pandey AK, Nagpure NS, Trivedi SP, Kumar R, Kushwaha B (2011) Profenofos induced DNA damage in freshwater fish, Channa punctatus (Bloch) using alkaline single cell gel electrophoresis. Mutat Res 726: 209-214. [Crossref]

12. Hernández AF1, Parrón T, Tsatsakis AM, Requena M, Alarcón R, et al. (2013) Toxic effects of pesticide mixtures at a molecular level: their relevance to human health. Toxicology 307: 136-145. [Crossref]

13. Wu JC, Hseu YC, Tsai JS, Chen LC, Chye SM, et al. (2011) Fenthion and terbufos induce DNA damage, the expression of tumor-related genes, and apoptosis in HEPG2 cells. Environ Mol Mutagen 52: 529-537. [Crossref]

14. (1991) Kidd H, James DR, (Eds.), The Agrochemicals Handbook, Third Edition. Roya Society of Chemistry Information Services, Cambridge, UK, pp: 3-11.

15. Taparia N, Mathur P, Shahani L (2014) Toxic action of quinalphos $25 \%$ EC (Flash), an organophosphate insecticide in induction of skeletal malformations in the embryos of Gallus domesticus. World J Pharm Pharmaceut Sci. 3: 2078-2088.

16. Behrends A, Riediger S, Grube S, Poeggeler B, Haldar C, et al. (2007) Photocatalytic mechanisms of indoleamine destruction by the quinalphos metabolite 2-hydroxyquinoxaline: a study on melatonin and its precursors serotonin and $\mathrm{N}$-acetylserotonin. J Environ Sci Health B 42: 599-606. [Crossref]

17. Rupa DS, Reddy PP, Reddi OS (1991) Cytogenetic effects of quinalphos in mice. Food Chem Toxicol 29: 115-117. [Crossref]

18. Wang TC, Lin CM, Lo LW (2003) Genotoxicity of mthoxyphosphinylisecticide in mammalian cells. Zool. Sci. 42: 462-469.

19. Kashyap MP, Singh AK, Kumar V, Tripathi VK, Srivastava RK, et al. (2011) Monocrotophos induced apoptosis in PC12 cells: role of xenobiotic metabolizing cytochrome P450s. PLoS One 6: e17757. [Crossref]

20. Joshi SC, Bansal B (2012) Reproductive toxicity of monocrotophos in male rats. Int J ToxicolAppl Pharm. 2: 6-11.

21. Malik M, Gairie FA (2011) Genotoxic effects of organophosphate insecticide Thiometon in some exotic fishes of Kashmir. Int J Pharm Sci Rev Res. 8: Article-019.

22. Moore PD, Patlolla AK, Tchounwou PB (2011) Cytogenetic evaluation of malathioninduced toxicity in Sprague-Dawley rats. Mutat Res 725: 78-82. [Crossref]

23. Reiter RJ, Tan DX, Terron MP, Flores LJ, Czarnocki Z (2007) Melatonin and its metabolites: new findings regarding their production and their radical scavenging actions. Acta Biochim Pol 54: 1-9. [Crossref]

24. Hardeland R, Pandi-Perumal SR (2005) Melatonin, a potent agent in antioxidative defense: actions as a natural food constituent, gastrointestinal factor, drug and prodrug. Nutr Metab (Lond) 2: 22. [Crossref]

25. Reiter RJ, Tan DX, Mayo JC, Sainz RM, Leon J, et al. (2003) Melatonin as an antioxidant: biochemical mechanisms and pathophysiological implications in humans. Acta Biochim Pol 50: 1129-1146. [Crossref]

26. Sarbia L, Maurer I, Bustos O (2009) Melatonin prevent damage elicited by the organophosphorous pesticide diazonin on mouse sperm DNA. Ecotoxicol Environ Saf. 72: 663-668. [Crossref]

27. Bhatti GK, Sidhu IPS, Bhatti JS (2013) Protective effect of melatonin against malathion induced alterations in antioxidant defense system and morphology of erythrocyte in Wistar rats. J Basic Appl Sci. 9: 438-446.

28. Cemek M, EminBuryukben A, Yurumen Y, Yavuz Y, Aslan A, et al. (2010) Tissue trace and major element levels in organophosphate insecticide fenthion (Lebaycid) toxicity in rats: prophylactic and therapeutic effect of exogenous melatonin. Ecotoxicol Environ Saf. 73: 206-212. [Crossref]

29. Sasaki YF, Sekihashi K, Izumiyama F, Nishidate E, Saga A, et al. (2000) The comet assay with multiple mouse organs: comparison of comet assay results and carcinogenicity with 208 chemicals selected from the IARC monographs and U.S. NTP Carcinogenicity Database. Crit Rev Toxicol. 30: 629-799. [Crossref]

30. Møller P (2005) Genotoxicity of environmental agents assessed by the alkaline come assay. Basic Clin Pharmacol Toxicol 96 Suppl 1: 1-42. [Crossref]

31. Collins AR (2004) The comet assay for DNA damage and repair: principles, applications, and limitations. Mol Biotechnol 26: 249-261. [Crossref]

32. Bolognesi C, Creus A, Ostrosky-Wegman P, Marcos R (2011) Micronuclei and pesticide exposure. Mutagenesis 26: 19-26. [Crossref]

33. Hayashi M (2007) In vivo rodent micronucleus assay. In: Obe, G., Vijaylaxmi. (Eds.), Chromosomal Alterations: Methods, Results and Importance in Human Health, Spinger, pp: 257-270.

34. Kirsch-Volders M, Decordier I, Elhajouji A, Plas G, Aardema MJ, et al. (2011) In vitro genotoxicity testing using the micronucleus assay in cell lines, human lymphocytes and 3D human skin models. Mutagenesis 26: 177-184. [Crossref]

35. Gaines TB (1969) Acute toxicity of pesticides. Toxicol Appl Pharmacol 14: 515-534 [Crossref]

36. Raizada RB1, Srivastava MK, Singh RP, Kaushal RA, Gupta KP, et al. (1993) Acute and subchronic oral toxicity of technical quinalphos in rats. Vet Hum Toxicol 35: 223 225. [Crossref]

37. Suke SG, Kumar A, Ahmed RS, Chakraborti A, Tripathi AK, et al. (2006) Protective effect of melatonin against propoxur-induced oxidative stress and suppression of humoral immune response in rats. Indian J Exp Biol 44: 312-315. [Crossref]

38. Phillips HJ (1973) Dye Exclusion Tests for Cell Viability, In: P.F. Kruse, M.J. Patterson (Eds.), Tissue Culture: Methods and Applications, Academic Press, New York, pp: 406-408.

39. Sasaki Y, Izumyama F, Nishidate E, Matsusaka N, Tsuda S (1997) Detection of rodent liver carcinogen genotoxicity by the alkaline single cell gel electrophoresis (Comet assay) in multiple mouse organs (liver, lung, spleen, kidney and bone marrow). Mutat Res. 391: 201-214. [Crossref]

40. Wojewódzka M, Buraczewska I, Kruszewski M (2002) A modified neutral comet assay: elimination of lysis at high temperature and validation of the assay with antisingle-stranded DNA antibody. Mutat Res 518: 9-20. [Crossref]

41. Schmid W (1975) The micronucleus test. Mutat Res 31: 9-15. [Crossref]

42. Gollapudi B, Kamra OP (1979) Application of a simple giemsa-staining method in the micronucleus test. Mutat Res 64: 45-46. [Crossref]

43. Bolognesi C (2003) Genotoxicity of pesticides: a review of human biomonitoring studies. Mutat Res 543: 251-272. [Crossref]

44. Prabhavathy Das G, Pasha Shaik A, Jamil K (2006) Cytotoxicity and genotoxicity induced by the pesticide profenofos on cultured human peripheral blood lymphocytes. Drug Chem Toxicol 29: 313-322. [Crossref]

45. Klaassen C (2008) In 'Casarett and Doull's Toxicology: The Basic Science of Poisons' McGraw Hill.

46. www.toxipedia.org/display/toxipedia/Monocrotophos

47. en.wikipedia.org/wiki/Quinalphos

48. Azqueta A, Lorenzo Y, Collins AR (2009) In vitro comet assay for DNA repair: warning concerning application to cultured cells. Mutagenesis 24: 379-381. [Crossref]

49. Luzhna L, Kathiria P, Kovalchuk O (2013) Micronuclei in genotoxicity assessment: from genetics to epigenetics and beyond. Front Genet 4: 131. [Crossref]

50. Collins AR (2009) Investigating oxidative DNA damage and its repair using the comet assay. Mutat Res 681: 24-32. [Crossref] 
51. El-Hussein, El-Khatib, Aziz MA, Bach Y, Kamal N (2005) In vivogenotoxicity of the synthetic pyrethroid pesticide "cypermethrin" in rat liver cells by comet assay. Arab J Biotech 8: 67-82.

52. Ayed-Boussema I, Rjiba K, Mnasri N, Moussa A, Bacha H (2012) Genotoxicity evaluation of dimethoate to experimental mice by micronucleus, chromosome aberration tests, and comet assay. Int $J$ Toxicol 31: 78-85. [Crossref]

53. Sandhu MA, Saeed AA, Khilji MS, Ahmed A, Latif MS, et al. (2013) Genotoxicity evaluation of chlorpyrifos: a gender related approach in regular toxicity testing. $J$ Toxicol Sci 38: 237-244. [Crossref]

54. JanakiDevi V, Nagarani N, YokeshBabu M, Kumaraguru AK, Ramakritinan CM (2013) A study of proteotoxicity and genotoxicity induced by the pesticide and fungicide on marine invertebrate (Donax faba). Chemosphere 90: 1158-1166. [Crossref]

55. Das PP, Shaik AP, Jamil K (2007) Genotoxicity induced by pesticide mixtures: invitro studies on human peripheral blood lymphocytes. Toxicol Ind Health 23: 449-458. [Crossref]
56. Bull S, Fletcher K, Boobis AR, Battershill JM (2006) Evidence for genotoxicity of pesticides in pesticide applicators: a review. Mutagenesis 21: 93-103. [Crossref]

57. Dröge W (2002) Free radicals in the physiological control of cell function. Physiol Rev 82: 47-95. [Crossref]

58. Mishra V, Srivastava N (2013) Organophosphate pesticides-induced changes in the redox status of rat tissues and protective effects of antioxidant vitamins. Environ Toxicol. [Crossref]

59. Sharma R, Sharma B (2012) In-vitro carbofuran induced genotoxicity in human lymphocytes and its mitigation by vitamins C and E. Dis Markers 32: 153-163. [Crossref]

60. Shittu M, Ambali SF, Ayo JO, Fatihu MY, Sulaiman MM, et al. (2012) Evaluation of chronic chlorpyrifos- induced reproductive toxicity in male Wistar rat: protective effects of vitamin C. J ExpIntegr Med. 3: 23-30.

61. Karamian A, Shokrzadeh M, Ahmadi A (2013) The potential chemoprotective effects of melatonin against genotoxicity induced by diazinon in human peripheral blood lymphocytes. Toxicol Ind Health. [Crossref]

Copyright: $(2015$ Mishra V. This is an open-access article distributed under the terms of the Creative Commons Attribution License, which permits unrestricted use, distribution, and reproduction in any medium, provided the original author and source are credited. 